Lingua Rima: Jurnal Pendidikan Bahasa dan Sastra Indonesia

Vol. 10 No. 2 Juli 2021

http://jurnal.umt.ac.id/index.php//grm

\title{
PENGGUNAAN E-LEARNING PADA MATA KULIAH BAHASA INDONESIA DI UNIVERSITAS MUHAMMADIYAH TANGERANG
}

\author{
Intan Sari Ramdhani ${ }^{1}$ \\ Universitas Muhammadiyah Tangerang $^{1}$ \\ intan.sariramdhani@gmail.com ${ }^{1}$ \\ Ira Anisa Purawinangun ${ }^{2}$ \\ Universitas Muhammadiyah Tangerang ${ }^{2}$ \\ irapurawinangun@yahoo.com² \\ Sumiyani $^{3}$ \\ Universitas Muhammadiyah Tangerang ${ }^{3}$ \\ Sumiyani.kinanti@gmail.com ${ }^{3}$
}

\begin{abstract}
ABSTRAK
Penelitian ini bertujuan untuk mendeskripsikan penggunaan e-learning pada mata kuliah Bahasa Indonesia di Universitas Muhammadiyah Tangerang. Metode penelitian yang digunakan dalam penelitian ini adalah metode deskriptif kualitatif. Objek penelitian ini adalah penggunaan -learning. Teknik pengumpulan data dilakukan dengan metode observasi dan dokumentasi. Teknik analisis data dengan cara reduksi data, penyajian data, dan penarikan kesimpulan. Hasil penelitian menunjukkan bahwa 1) Mata kuliah Bahasa Indonesia di Universitas Muhammadiyah Tangerang menerapkan pembelajaran blended learning dengan menggabungkan penggunaan kelas e-learning dan tatap muka 2) ) E-learning dapat menjadi sumber belajar mahasiswa, 3) E-learning adalah salah satu upaya dalam menumbuhkan kemandirian belajar mahasiswa, 4) E-learning mempermudah dosen memberikan tugas atau ujian dan mempermudah mahasiswa mengumpulkan tugas atau ujian, 4) E-learning melengkapi pembelajaran konvensional di dalam kelas.

Kata kunci: bahasa Indonesia, e-learning, penggunaan
\end{abstract}

\section{A. PENDAHULUAN}

Dewasa ini Indonesia sedang mempersiapkan diri menuju era revolusi Industri 5.0, di mana manusia harus dapat bersinergi dengan teknologi informasi yang canggih dengan memanfaatkan aplikasi dan internet dengan sebaik-baiknya. Oleh karena itu, manusia harus melakukan pembiasaan diri dengan banyak memanfaatkan fasilitas teknologi informasi di segala bidang termasuk bidang pendidikan terutama pendidikan di perguruan tinggi. Penggunaan teknologi informasi dalam menempuh pendidikan di perguruan tinggi pada proses pembelajaran dianggap mampu memudahkan mahasiswa dalam memperoleh informasi dan ilmu pengetahuan yang terus berkembang. Oleh karena itu, mahasiswa dituntut untuk lebih kreatif dan mandiri. Kemandirian itu bisa dilatih dalam pelaksanaan proses 


\section{Lingua Rima: Jurnal Pendidikan Bahasa dan Sastra Indonesia \\ Vol. 10 No. 2 Juli 2021 \\ http://jurnal.umt.ac.id/index.php/lgrm}

pembelajaran. Oleh karena itu, upaya yang dapat dilakukan untuk menumbuhkan kemandirian belajar mahasiswa perlu dilakukan. Penggunaan teknologi informasi dalam pelaksanaan pembelajaran menjadi jawaban akan keharusan mahasiswa untuk lebih banyak belajar sendiri, secara mandiri menggali ilmu pengetahuan yang sedang dipelajari.

Informasi dalam pembelajaran adalah sumber informasi, yaitu untuk mencari informasi-informasi yang sedang dibutuhkan, media dalam pembelajaran, yaitu sebagai alat bantu dalam memfasilitasi penyampaian informasi agar dapat diterima dan dimengerti dengan mudah, pengembang keterampilan dalam pembelajaran, yaitu pengembangan keterampilanketerampilan berbasis teknologi informasi dengan aplikasi-aplikasi dalam kurikulum. Elearning dapat mendorong budaya kritis mahasiswa, karena mahasiswa memiliki cara berpikir yang berbeda-beda (Prasetya 2015:334). Pemanfaatan teknologi informasi dalam pembelajaran di Universitas Muhammadiyah Tangerang diwujudkan dengan diterapkannya penggunaan e-learning dalam pembelajaran. Penggunaan e-learning ini dipercaya mampu memudahkan dosen dan mahasiswa dalam meningkatkan kualitas pembelajaran terutama dalam pembelajaran bahasa Indonesia.

E-learning atau Electronic Learning merupakan sistem pembelajaran yang berkaitan dengan teknologi informasi. Menurut Ardiansyah (2013), e-learning adalah sistem pembelajaran yang digunakan sebagai sarana untuk proses belajar mengajar yang dilaksanakan tanpa harus bertatap muka secara langsung antara guru dan siswa. Untuk bisa menggunakan sistem pembelajaran e-learning harus menggunakan media berupa komputer dan internet. Penggunaan e-learning dalam pembelajaran bahasa Indonesia dapat menjadikan pembelajaran menjadi lebih efektif dan efisien. Manfaat e-learning menurut Pranoto, dkk (2009:309) adalah: 1) Penggunaan e-learning untuk menunjang pelaksanaan proses belajar dapat meningkatkan daya serap mahasiswa atas materi yang diajarkan. 2) Meningkatkan partisipasi aktif dari mahasiswa, 3) Meningkatkan kemampuan belajar mandiri mahasiswa, 4) Meningkatkan kualitas materi pendidik dan pelatihan, 5) Meningkatkan kemampuan menampilkan informasi dengan perangkat teknologi informasi (Septiani, 2018).

Bahasa Indonesia merupakan mata kuliah wajib yang dipelajari di semua fakultas dan semua prodi di semester pertama. Tujuan dipelajarinya bahasa Indonesia oleh mahasiswa adalah karena 1) mahasiswa harus mempelajari dan mengembangkan bahasa yang dimiliki oleh bangsanya sendiri, yaitu bangsa Indonesia,2) memberikan pengetahuan kepada mahasiswa tentang pemahaman konsep ilmiah dan mampu menerapkan dalam karya ilmiahnya, 3) Bahasa Indonesia merupakan alat komunikasi yang dapat mengembangkan 


\section{Lingua Rima: Jurnal Pendidikan Bahasa dan Sastra Indonesia \\ Vol. 10 No. 2 Juli 2021 \\ http://jurnal.umt.ac.id/index.php/lgrm}

kecerdasan, karakter, dan kepribadian mahasiswa. Namun, seringkali mata kuliah bahasa Indonesia ini kurang diminati mahasiswa, terlebih materi yang dipelajari dalam mata kuliah ini sangat beragam, contohnya materi penulisan karya ilmiah yang akan berguna untuk mahasiswa saat menyusun makalah presentasi atau skripsi kelak. Mahasiswa harus mempelajari dan memahami materi tersebut mulai dari teknis penulisan sesuai dengan Pedoman Umum Ejaan Bahasa Indonesia (PUEBI), tata kalimat, mengutip referensi, menulis daftar pustakan dan lain-lain.

Penelitian sebelumnya dilakukan oleh Darmika, Guatama, dan Sutama (2018) dengan judul Penggunaan E-Learning dalam Pembelajaran Bahasa Indonesia di SMA Negeri Bali Mandara dengan hasil penelitian adalah (1) isi e-learning dalam pembelajaran bahasa Indonesia,ada lima yaitu: (a) kode kelas, (b) materi bahasa Indonesia,(c) materi tambahan (d) tugas online, dan (e) hasil asessment. Sementara daya dukung e-learning dalam pembelajaran bahasa Indonesia di SMA Negeri Bali Mandara ada tiga, yaitu: (a) mempermudah guru dalam mengajar, (b) mendukung materi dalam silabus, (c) memfasilitasi evaluasi online. (2) Penerapan e-learning dalam pembelajaran bahasa Indonesia di SMA Negeri Bali Mandara, yaitu dalam bentuk blended learning (3) Respons peserta didik terhadap penggunaan elearning dalam pembelajaran bahasa Indonesia, yaitu sangat positif $(31,45 \%)$ dengan rincian terdapat $21(47,72 \%)$ memberikan resposn sangat setuju dan $23(52,27 \%)$ memberikan respons setuju.

\section{B. METODE PENELITIAN}

Metode penelitian yang digunakan dalam penelitian ini adalah metode deskriptif kualitatif. Tujuan penggunaan metode deskriptif kualitatif agar mampu mendeskripsikan dan memahami tentang penggunaan e-learning pada mata kuliah Bahasa Indonesia. Teknik pengumpulan data dalam penelitian ini menggunakan teknik observasi, pustaka, dan dokumentasi. Data penelitian ini adalah penggunaan e-learning. Teknik analisis data dengan cara reduksi data, interpretasi data, dan menyimpulkan hasil penelitian.

\section{HASIL PENELITIAN DAN PEMBAHASAN}

Berdasarkan hasil analisis data, hasil observasi, wawancara, kajian pustaka, dan dokumentasi penggunaan e-learning pada mata kuliah Bahasa Indonesia di Universitas Muhammadiyah Tangerang (UMT) menunjukkan bahwa UMT menerapkan blended learning yaitu menggabungkan pembelajaran secara tatap muka dan memanfaatkan teknologi informasi berupa pembuatan kelas e-learning dalam proses pembelajaran yang dinamakan kelas e-learning UMT di situs elearning.umt.ac.id. 


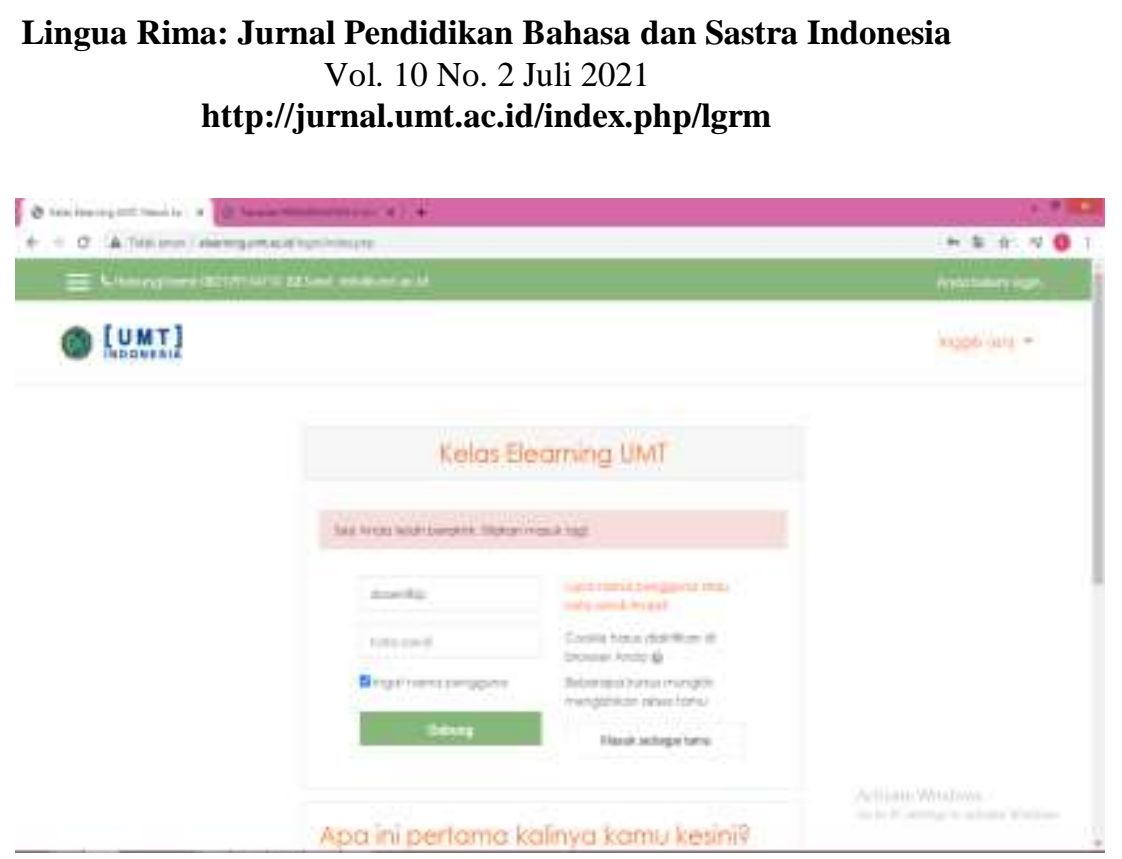

Gambar 1. E-learning UMT

Penggunaan e-learning ini dapat memudahkan proses pembelajaran. Berbagai kemudahan yang ada dalam e-learning untuk meningkatkan pembelajaran Bahasa Indonesia adalah e-learning bisa menjadi sumber belajar mahasiswa dalam pembelajaran bahasa Indonesia, yakni mahasiswa bisa membaca materi yang dipelajari dengan leluasa sesuai dengan kebutuhan belajar masing-masing, bisa diakses kapan saja dan di mana saja. Mahasiswa lebih mudah menyerap materi yang dipelajari dalam mata kuliah Bahasa Indonesia, e-learning adalah upaya menumbuhkan kemandirian belajar mahasiswa, yakni dengan adanya e-learning mahasiswa akan lebih banyak belajar sendiri tanpa banyak formalitas kelas dan karena materi bisa diakses kapan pun tersedia selama 24 jam.

Mahasiswa bisa menyesuaikan sendiri waktu yang paling efektif untuk belajar sesuai dengan kebutuhan masing-masing sehingga kemandirian dalam belajar itu akan membentuk kepribadian mahasiswa, penguasaan materi dan daya serap mahasiswa terhadap materi bahasa Indonesia yang dipelajari. E-learning memudahkan dosen dan mahasiswa dalam hal pemberian serta pengumpulan tugas atau ujian juga membagikan materi ajar, yakni dengan menggunakan e-learning menjadi lebih efektif dan efisien, tugas dan ujian berada di satu tempat, tidak akan tercecer. Hal ini memudahkan dosen memberikan penilaian terhadap hasil kerja mahasiswa dan mahasiswa bisa jadi lebih mudah mengecek nilai yang diberikan dosen. Selain itu juga, mempermudah dosen dengan mahasiswa dan mahasiswa dengan mahasiswa untuk berdiskusi membahas materi yang sudah dibagikan di e-learning. Kemudahankemudahan seperti di atas dapat dilihat dari banyaknya fitur $e$-learning yang digunakan UMT di bawah ini. 
Lingua Rima: Jurnal Pendidikan Bahasa dan Sastra Indonesia

Vol. 10 No. 2 Juli 2021

http://jurnal.umt.ac.id/index.php//grm

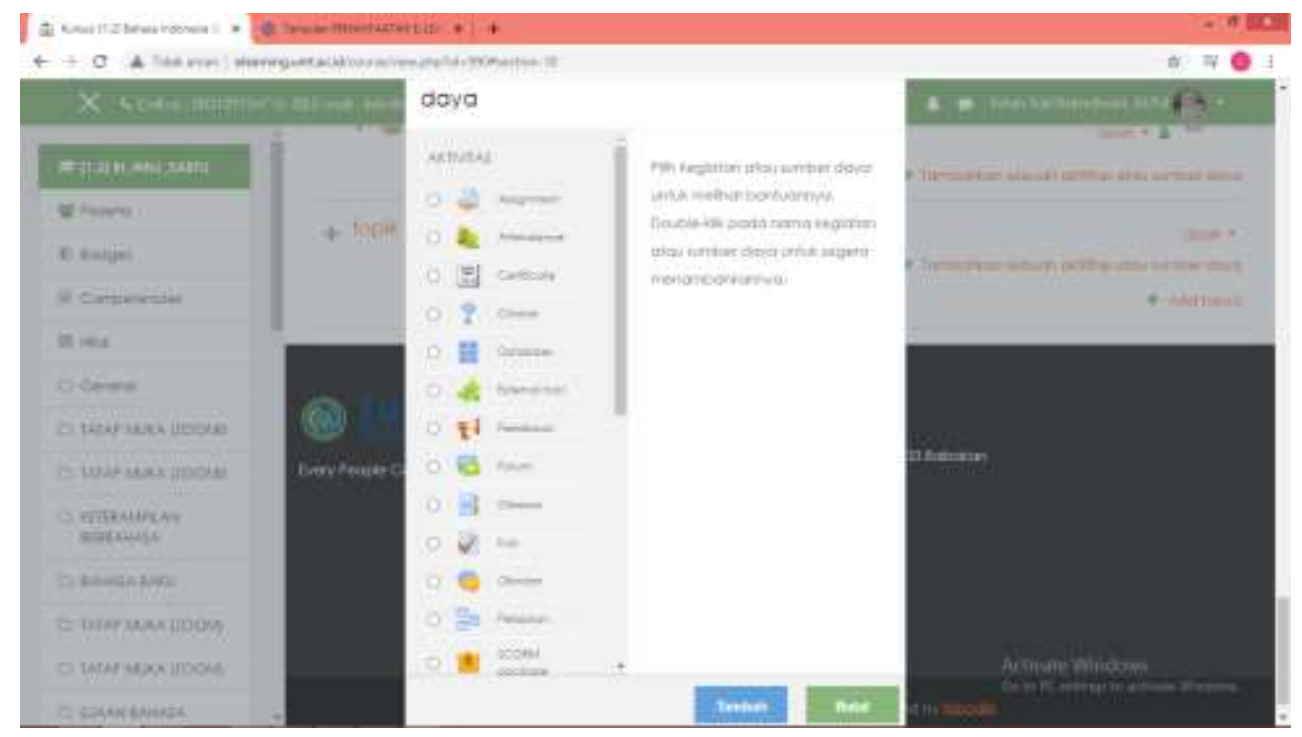

Gambar 2. Fitur E-learning UMT

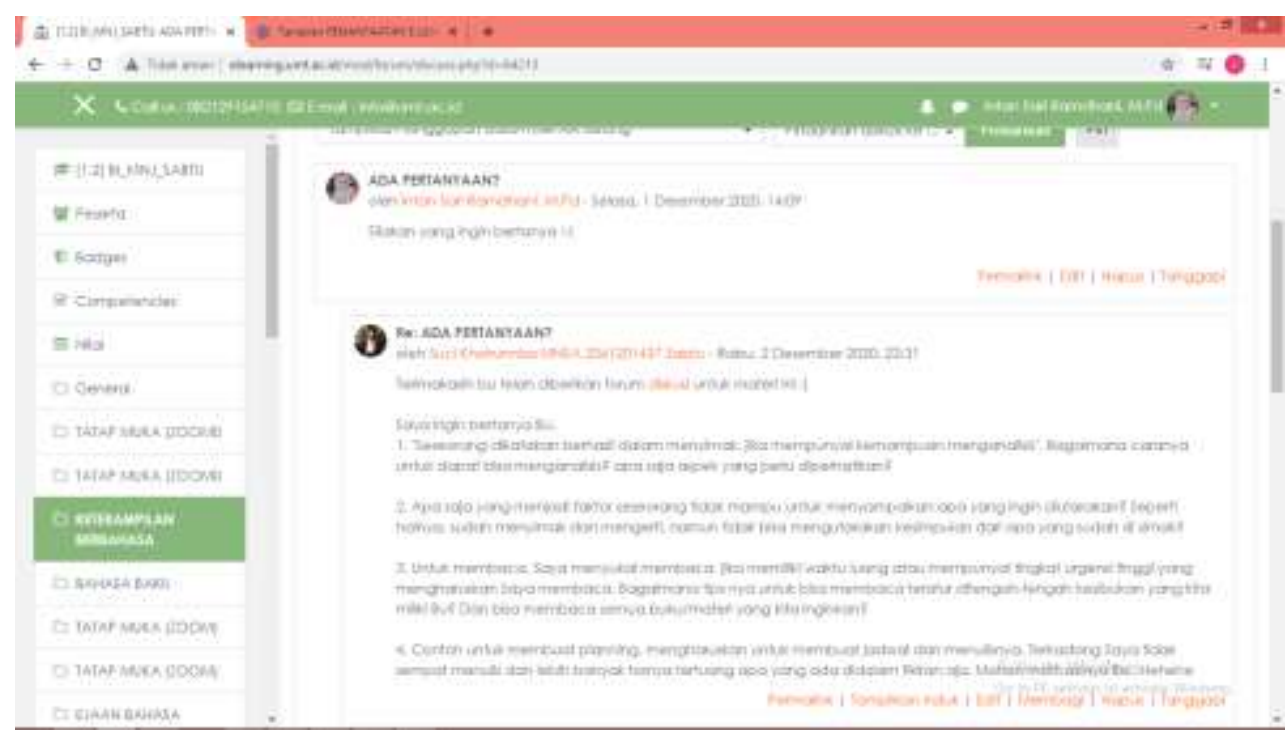

Gambar 3. Diskusi E-learning UMT 
Lingua Rima: Jurnal Pendidikan Bahasa dan Sastra Indonesia

Vol. 10 No. 2 Juli 2021

http://jurnal.umt.ac.id/index.php/lgrm

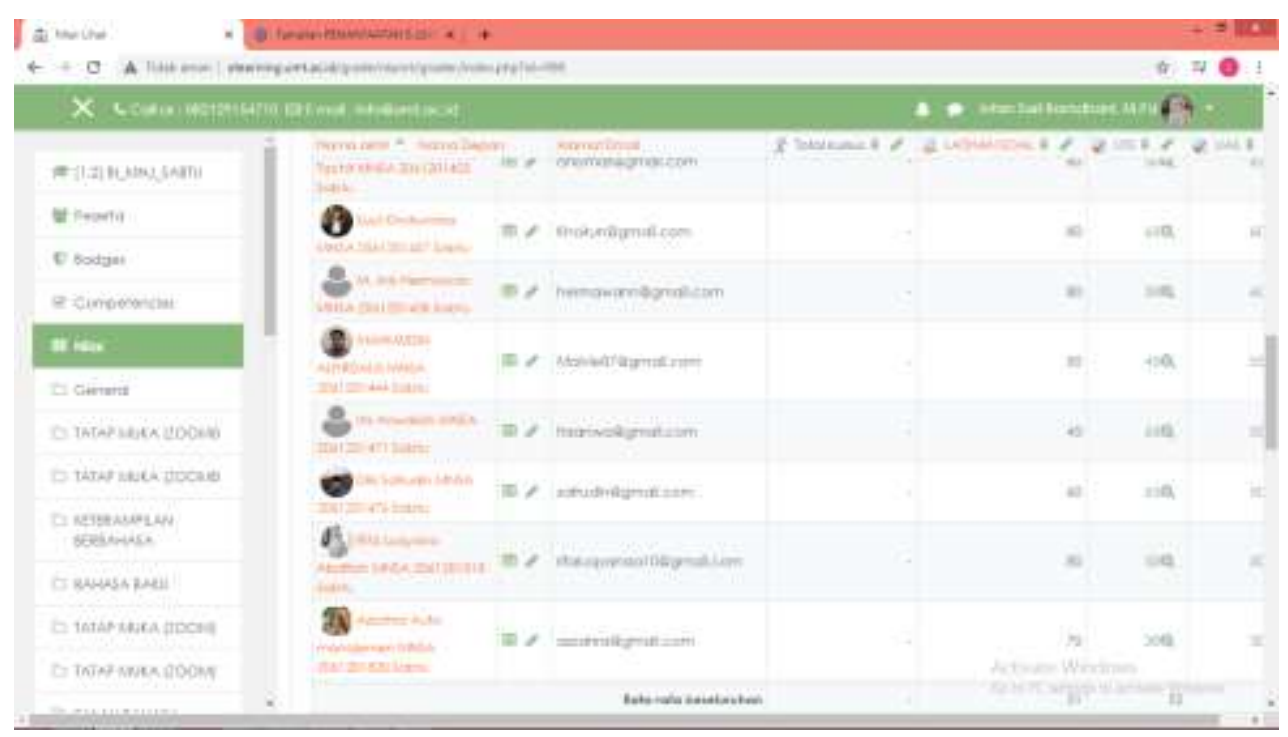

Gambar 4. Nilai

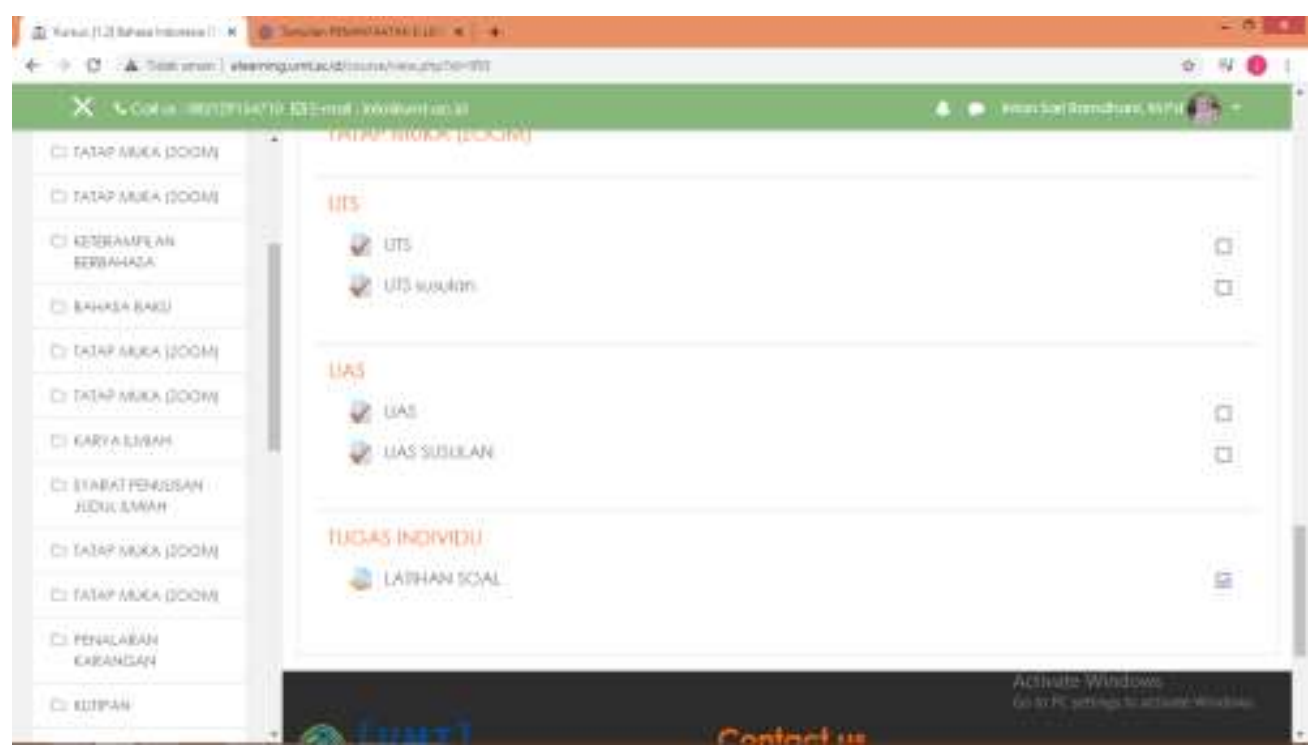

Gambar 5. Pemberian Tugas dan Ujian

Selanjutnya e-learning dapat juga melengkapi pembelajaran konvensional atau tatap muka di dalam kelas. Materi-materi yang sudah diulas di dalam kelas bisa kembali dibagikan dalam e-learning agar mahasiswa dapat membaca dan memahami kembali materi yang diajarkan. Dosen juga bisa memberikan materi baru ke mahasiswa yang dibagikan dalam $e$ learning. Jika jumlah tatap muka terbatas atau adanya ketertinggalan dalam pembelajaran dikarenakan tanggal merah dan lain sebagainya. Jadi e-learning dapat dijadikan wadah pengajaran mata kuliah Bahasa Indonesia juga sebagai alat bantu atau media dalam pembelajaran bahasa Indonesia yang dapat mengubah pemikiran bahwa Bahasa Indonesia 
Lingua Rima: Jurnal Pendidikan Bahasa dan Sastra Indonesia

Vol. 10 No. 2 Juli 2021

http://jurnal.umt.ac.id/index.php/lgrm

tidak melulu diajarkan dengan metode konvensional, banyak menulis atau dikte tetapi dengan adanya e-learning, pembelajaran mata kuliah bahasa Indonesia menjadi lebih efektif, efisien, ringkas dikemas dengan media yang menarik. Adapun nilai mahasiswa menggunakan pembelajaran e-learning adalah sebagai berikut.

Tabel 4.1 Nilai Mahasiswa dengan menggunakan E-learning

\begin{tabular}{|c|l|c|c|}
\hline NO & \multicolumn{1}{|c|}{ NAMA MAHASISWA } & NIM & NILAI \\
\hline 1 & Bayu Saputra & 2061201566 & 84 \\
\hline 2 & Rahul Abdi putra & 2061201403 & 83 \\
\hline 3 & Nurhayati Hasnah & 2061201352 & 85 \\
\hline 4 & Nashir As Shiddiqi & 2061201413 & 75 \\
\hline 5 & Sidik Wicaksono & 2061201168 & 90 \\
\hline 6 & Yuli Agustin & 2061201612 & 84 \\
\hline 7 & Estiara Putri Kusuma & 2061201613 & 85 \\
\hline 8 & Tito Taufik Rohman & 2061201670 & 82 \\
\hline 9 & Reza Pahlevi & 2061201618 & 82 \\
\hline 10 & Nuryadin & 2061201730 & 78 \\
\hline 11 & Ratna Sari & 2061201367 & 85 \\
\hline 12 & Yoga Afryan Novaskhan Pranatama & 2061201453 & 80 \\
\hline 13 & Nasihatul Islamiah & 2061201459 & 88 \\
\hline 14 & Zihan Monika Apriliya & 2061201639 & 88 \\
\hline 15 & Imam Rosyid Al Fattaah & 2061201664 & 84 \\
\hline 16 & Saiful Amri & 2061201665 & 83 \\
\hline 17 & Salsabilla Balqis Sajarhan & 2061201452 & 85 \\
\hline 18 & Muhammad Zidan Dzaki & 2061201690 & 78 \\
\hline 19 & Haidir Farid & 2061201736 & 82 \\
\hline 20 & Rania Aulia Putri & 1961201972 & 75 \\
\hline & & & \\
\hline
\end{tabular}

Pada tabel di atas, nilai yang sudah diakumulasi dari nilai kehadiran, nilai tugas, UTS dan UAS. Sebagian besar mahasiswa mendapatkan nilai di atas 80 artinya nilai A, dan hanya beberapa orang mendapatkan nilai di angka 70 artinya nilai B. Hal ini membuktikan bahwa mahasiswa telah menggunakan dan memanfaatkan e-learning pada mata kuliah Bahasa Indonesia dengan cukup baik. Meskipun banyak kelebihan yang dimiliki e-learning, ternyata kendala-kendala pada saat proses pembelajaran menggunakan e-learning juga ada. Sebagian mahasiswa UMT masih belum merasa butuh menggunakan e-learning, jadi ada sedikit dari mahasiswa minim belajar menggunakan e-learning, tetapi hanya fokus pada materi yang disampaikan saat tatap muka. Hal tersebut diakibatkan karena koneksi internet yang buruk wilayah tempat tinggal mahasiswa, tidak tersedianya sarana atau fasilitas elektronik seperti 


\section{Lingua Rima: Jurnal Pendidikan Bahasa dan Sastra Indonesia \\ Vol. 10 No. 2 Juli 2021 \\ http://jurnal.umt.ac.id/index.php/lgrm}

komputer atau laptop, kurangnya penguasaan komputer dan internet atau bisa juga karena rendahnya motivasi belajar secara mandiri. Oleh karena itu, UMT tetap menerapkan pembelajaran secara tatap muka untuk mengantisipasi dan meminimalisasi kendala-kendala yang ada pada penggunaan e-learning. Dosen tetap diharuskan untuk melakukan pendampingan pembelajaran secara langsung kepada mahasiswa dan tetap mengarahkan serta memotivasi mahasiswa untuk mau belajar secara mandiri dengan bantuan sistem e-learning.

\section{SIMPULAN}

Hasil penelitian ini membuktikan bahwa e-learning bisa digunakan dalam pembelajaran mata Bahasa Indonesia dengan tujuan untuk meningkatkan kualitas pembelajaran dan meningkatkan kemampuan professional tenaga pengajar, meningkatkan sumber daya manusia dalam memanfaatkan teknologi informasi serta meningkatkan kemampuan berpikir kritis mahasiswa melalui pembelajaran secara mandiri. Mata kuliah Bahasa Indonesia di Universitas Muhammadiyah Tangerang menerapkan pembelajaran blended learning dengan menggabungkan penggunaan kelas e-learning dan tatap muka agar meminimalisasi kendalakendala pada proses pembelajaran menggunakan e-learning. Kelebihan e-learning yaitu (1) e-learning dapat menjadi sumber belajar yang efektif bagi mahasiswa, (2) e-learning adalah salah satu upaya dalam menumbuhkan kemandirian belajar mahasiswa, (3) e-learning mempermudah dosen memberikan tugas atau ujian dan mempermudah mahasiswa mengumpulkan tugas atau ujian, (4) e-learning melengkapi pembelajaran konvensional di dalam kelas. Saran bagi dosen lain diharapkan dapat mengoptimalkan pembelajaran menggunakan e-learning. Selain itu, peneliti mengharapkan penggunaan e-learning ini bisa dijadikan solusi agar mutu pembelajaran khususnya diperguruan tinggi pada mata kuliah Bahasa Indonesia.

\section{E. DAFTAR PUSTAKA}

Ardiansyah, Ivan. 2013. Eksplorasi Pola Komunikasi dalam Diskusi Menggunakan Moddle pada Perkuliahan Simulasi Pembelajaran Kimia. Bandung: Universitas Pendidikan Indonesia.

Darmika, I Putu, Gunatama, Gede dan Sutama, I Made. 2018. Penggunaan e-learning dalam Pembelajaran Bahasa Indonesia di SMA Negeri Bali Mandara. Jurnal Pendidikan Bahasa dan Sastra Indonesia. Vol 8 No 2

Pranoto, Alvini, dkk. 2009. Sains dan Teknologi. Jakarta: PT Gramedia Pustaka Utama.

Prasetya, Marzuqi Agung. 2015. E-learning Sebagai Sebuah Inovasi Metode Active Learning. Edukasia: Jurnal Penelitian Pendidikan Islam. Volume 10 Nomor 2 
Lingua Rima: Jurnal Pendidikan Bahasa dan Sastra Indonesia

Vol. 10 No. 2 Juli 2021

http://jurnal.umt.ac.id/index.php//grm

Septiani, Eka. 2018. Pembelajaran E-learning dalam Pembelajaran Bahasa dan Sastra Indonesia. Pesona : Pekan Seminar Nasional Pendidikan Bahasa dan Sastra Indonesia. Volume 1 Nomor 1. 